\title{
The Association of Fractional Pulse Pressure with Acute Kidney Injury in Patients Undergoing Coronary Intervention due to ST-Segment Elevated Myocardial Infarction
}

\author{
Cengiz Burak ${ }^{a} \quad$ Muhammed Süleymanoğlu ${ }^{a} \quad$ Mahmut Yesin $^{a} \quad$ Murat Cap $^{b}$ \\ İbrahim Yıldız ${ }^{c}$ İbrahim Rencüzoğulları ${ }^{a}$ Metin Çağdaşa ${ }^{a}$ Yavuz Karabağ $^{a}$ \\ Şerif Hamideyin ${ }^{\mathrm{a}}$ Doğan Illişs $^{\mathrm{a}}$ Erkan Baysal $^{\mathrm{b}}$

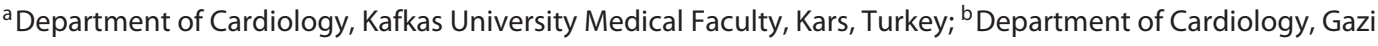 \\ Yaşargil Training and Research Hospital, Diyarbakır, Turkey; 'Department of Cardiology, Osmaniye State Hospital, \\ Osmaniye, Turkey
}

\section{Highlights of the Study}

- This study shows that invasively measured fractional pulse pressure is associated with acute kidney injury (AKI).

- Fractional pulse pressure is an independent predictor of AKI in STEMI patients.

- The in-hospital mortality rate is significantly higher in patients with AKI than those without.

\section{Keywords}

Fractional pulse pressure $\cdot$ Acute kidney injury $\cdot$ Myocardial infarction · ST-segment elevation myocardial infraction

\begin{abstract}
Objective: Acute kidney injury (AKI), which is prevalent in STsegment elevated myocardial infarction (STEMI) patients who have undergone primary percutaneous coronary intervention $(\mathrm{PCl})$, is associated with poor cardiovascular outcomes. As high pulse pressure (PP) is associated with adverse cardiovascular events, the present study's aim was to evaluate the relationship between fractional PP (PPf) and AKI in patients with STEMI who underwent primary $\mathrm{PCI}$. Subjects and Methods: All laboratory findings as well as echocardiographic and angiographic data of 1,170 consecutive STEMI patients were retrospectively screened. PPf was calculated
\end{abstract}

karger@karger.com www.karger.com/mpp

Karger $\frac{1}{\%}$

GOPEN ACCESS
(C) 2020 The Author(s)

Published by S. Karger AG, Basel

This is an Open Access article licensed under the Creative Commons Attribution-NonCommercial-4.0 International License (CC BY-NC) (http://www.karger.com/Services/OpenAccessLicense), applicable to the online version of the article only. Usage and distribution for commercial purposes requires written permission. from the pressures invasively measured after sheath insertion and before performing coronary angiography. Results: From 1,170 eligible STEMI patients (mean age 56 years, $18.2 \%$ female), AKI developed in 143 (12.2\%) patients. The PPf and pulsatility index were significantly higher in patients with $\mathrm{AKI}$ than those without $(0.53 \pm 0.10$ vs. $0.61 \pm 0.10, p<0.001$, and $0.80 \pm 0.03$ vs. $0.82 \pm 0.03, p<0.001$, respectively). PPf was also found to be associated with AKI in univariable (OR 2.183, 95\% Cl 1.823-2.614, $p<0.001$ ) and multivariable (OR 1.874, $95 \% \mathrm{Cl} 1.513-2.322, p<0.001)$ analysis. In-hospital mortality was higher in patients with AKI than those without. Conclusion: Invasively measured PPf, which can be easily measured and has no additional cost in STEMI patients undergoing coronary intervention, is an independent predictor of AKI. In addition, PPf is superior to other blood pressure values and derivatives in $\mathrm{AKI}$ prediction.

(c) 2020 The Author(s)

Published by S. Karger AG, Basel 


\section{Introduction}

Contrast media that is widely used in many diagnostic and interventional procedures may cause acute kidney injury (AKI) because of its known nephrotoxicity. The incidence of AKI in cardiovascular procedures ranges from 3.3 to $14.5 \%$, which may increase up to $19 \%$ in primary percutaneous coronary intervention (PCI) [1-3]. In ST-segment elevation myocardial infraction (STEMI) patients who are treated with primary PCI, AKI is associated with various ominous endpoints, including increased in-hospital and long-term morbidity and mortality [4-6]. Therefore, an early prediction, identification, and prevention of AKI is crucial for the management of these patients.

Pulse pressure (PP), which is associated with increased aortic stiffness, is obtained by subtracting diastolic blood pressure (DBP) from systolic blood pressure (SBP). It has been shown that increased aortic PP is independently associated with adverse cardiovascular events [7]. Since different combinations of SBP and DBP can give the same $\mathrm{PP}$ value, a new parameter of the pulsatile component of blood pressure has been developed to reflect arterial stiffness more directly than PP. Fractional PP (PPf), which is calculated as PP divided by the mean arterial pressure (MAP), theoretically cancels out the influence of cardiac output and peripheral vascular resistance, and it reflects arterial stiffness more directly than PP [8].

To date, various risk factors have been identified to be associated with the development of AKI, including preexisting renal disease, diabetes mellitus, age, the type and volume of contrast agents, anemia, hypotension, intraaortic balloon pump (IABP) use, left ventricular systolic dysfunction, and nephrotoxic drugs [9]. Increased arterial stiffness is related to a damaged kidney microvasculature, which may result in renal injury and end-stage renal disease [10]. In the present study, we aimed to evaluate the association between PPf and AKI in STEMI patients who underwent primary PCI.

\section{Subjects and Methods}

\section{Study Population}

This study was a retrospective analysis of 1,368 patients who were diagnosed with STEMI and underwent primary PCI between January 2013 and December 2018 in the cardiology departments of Kafkas University Hospital and Osmaniye State Hospital. After exclusion of patients with end-stage renal failure who were on hemodialysis or peritoneal dialysis $(n=18)$, or who were treated with emergent coronary artery bypass grafting surgery $(n=12)$ or who had a previous history of revascularization $(n=168), 1,170$ patients were eligible for this analysis. Our hospital records indicated that all patients received medical treatment according to recent STEMI treatment guidelines. As per hospital protocol, all patients were intravenously hydrated with normal saline if they had no pulmonary edema or were not in cardiogenic shock. A low osmolar, nonionic contrast media was used in all procedures.

\section{Data Collection and Definitions}

The patients' detailed biochemical markers were measured on admission. In addition, hemoglobin and serum creatinine levels were tested daily. Cardiac biomarkers were obtained every $6 \mathrm{~h}$ until their peak levels and then daily. The Modification of Diet in Renal Disease Study Equation was used to calculate the estimated glomerular filtration rate (eGFR) from the serum creatinine level which was taken on admission. To assess renal dysfunction, serum creatinine levels of all patients were monitored during hospitalization. AKI was defined as either a $25 \%$ increase from baseline or a $0.5-\mathrm{mg} / \mathrm{dL}$ increase in absolute value within $48-72 \mathrm{~h}$ after the contrast media exposure. Detailed echocardiographic evaluations were performed within $24-48 \mathrm{~h}$ after the primary PCI, and the left ventricular ejection fraction (LVEF) was calculated using the modified Simpson's technique.

The patients' systolic, diastolic, and mean arterial blood pressure values, which were measured invasively after femoral or radial sheath insertion and before diagnostic coronary angiography, were obtained from the angiography documents and nursing care forms. The first measurement of 3-5 beats averaged after the calibration was taken. Hemodynamic parameters were calculated using the following formulae:

$\mathrm{PP}=\mathrm{SBP}-\mathrm{DBP}$

$\mathrm{PPf}=\mathrm{PP} / \mathrm{MAP}$

Pulsatility index $=\mathrm{PP} / \mathrm{DBP}$

\section{Angiographic Analysis}

All patients underwent PCI via the radial or femoral approach. Prior to the intervention, all patients had been treated with acetylsalicylic acid, clopidogrel or ticagrelor, and unfractionated heparin at a dose of $70-100 \mathrm{U} / \mathrm{kg}$. The decision on the use of IABP was made by the operator during or after the procedure. All procedures were performed with a non-ionic, low-osmolar contrast media. The procedure duration and the amount of contrast media used were retrieved from the patients' angiography reports or hospital files. The patients' angiography images, the synergy between PCI with taxus and cardiac surgery (SYNTAX) score, infarct-related artery (IRA) characteristics, and the presence of chronic total occlusion were evaluated.

\section{Statistical Analysis}

SPSS statistical software version 21.0 (SPSS Inc., Chicago, IL, USA) was used to analyze the data. Continuous and categorical variables are presented as the mean \pm SD and frequency and percentage, respectively. The distribution of continuous variables was evaluated by the Kolmogorov-Smirnov test. Variables with a normal distribution are presented as the mean \pm SD. Those without a normal distribution are presented as the median (interquartile range). The Student $t$ test or the Mann-Whitney U test were used to compare all continuous variables between the AKI and non-AKI groups. Either the $\chi^{2}$ test or Fisher's exact test was used to compare the categorical data. A two-tailed $p$ value $<0.05$ was considered statistically significant. Univariable and multivariable logistic re- 
Table 1. Baseline characteristics and laboratory results of all patients and patients classified according to AKI

\begin{tabular}{|c|c|c|c|c|}
\hline & $\begin{array}{l}\text { All patients } \\
(n=1,170)\end{array}$ & $\begin{array}{l}\text { Patients without } \\
\text { AKI }(n=1,027)\end{array}$ & $\begin{array}{l}\text { Patients with } \\
\text { AKI }(n=143)\end{array}$ & $p$ value \\
\hline Age, years & $56 \pm 12$ & $55 \pm 12$ & $63 \pm 13$ & $<0.001$ \\
\hline Female & $213(18.2)$ & $175(17.0)$ & $38(26.6)$ & 0.006 \\
\hline Diabetes mellitus & $274(23.4)$ & $220(21.4)$ & $54(37.8)$ & $<0.001$ \\
\hline Hypertension & $463(39.6)$ & $382(37.2)$ & $81(56.6)$ & $<0.001$ \\
\hline Dyslipidaemia & $506(43.2)$ & $448(43.6)$ & $58(40.6)$ & 0.489 \\
\hline Smoking & $663(56.7)$ & $609(59.3)$ & $54(37.8)$ & $<0.001$ \\
\hline White blood cell count, $\times 10^{3} / \mu \mathrm{L}$ & $12.4 \pm 3.8$ & $12.2 \pm 3.5$ & $13.7 \pm 5.2$ & 0.012 \\
\hline Hemoglobin, g/dL & $13.8 \pm 1.8$ & $13.9 \pm 1.7$ & $13.0 \pm 2.0$ & $<0.001$ \\
\hline Glucose, mg/dL & $127(104-171)$ & $125(103-161)$ & $143(114-230)$ & $<0.001$ \\
\hline $\mathrm{CRP}, \mathrm{mg} / \mathrm{dL}$ & $9.8(5.6-16.5)$ & $9.2(5.4-15.4)$ & $16.7(8.9-27.5)$ & $<0.001$ \\
\hline Creatinine (admission), $\mathrm{mg} / \mathrm{dL}$ & $0.91 \pm 0.27$ & $0.88 \pm 0.20$ & $1.14 \pm 0.50$ & $<0.001$ \\
\hline Creatinine (peak), mg/dL & $1.06 \pm 0.51$ & $0.95 \pm 0.21$ & $1.87 \pm 1.06$ & $<0.001$ \\
\hline $\mathrm{eGFR}, \mathrm{mL} / \mathrm{min}$ & $89.0 \pm 24.5$ & $91.1 \pm 22.3$ & $73.8 \pm 32.8$ & $<0.001$ \\
\hline Troponin I (peak), ng/mL & $78(35-178)$ & $72(35-158)$ & $162(65-312)$ & $<0.001$ \\
\hline LVEF, \% & $47.2 \pm 8.3$ & $48.1 \pm 7.8$ & $41.3 \pm 9.4$ & $<0.001$ \\
\hline
\end{tabular}

Data are presented as the mean $\pm \mathrm{SD}, n(\%)$, or median (range). AKI, acute kidney injury; eGFR, estimated glomerular filtration rate; LVEF, left ventricular ejection fraction; CRP, C-reactive protein.

gression analyses were performed to identify the independent predictors of AKI. To define the PPf value that predicted postcontrast AKI with the best specificity and sensitivity, receiver operating characteristic (ROC) curve analysis was used.

\section{Results}

In total, 1,170 consecutive STEMI patients were included in the study (mean age 56 years, $18.2 \%$ female). We observed that AKI occurred in 143 (12.2\%) patients. The study cohort was classified into 2 groups: patients with AKI and those without it. Hemodialysis was required in $6.3 \%(n=9)$ of AKI patients. The AKI group was older and composed of more female patients. The frequencies of hypertension and diabetes mellitus were higher and LVEF and eGFR levels were lower in the AKI group than those without AKI. In terms of laboratory parameters, hemoglobin levels were lower, but plasma glucose, C-reactive protein (CRP), creatinine, and troponin levels were higher in AKI patients (Table 1).

Although there was no significant difference between the 2 groups in terms of SBP, MAP, and PP values, DBP values were lower in patients with AKI. PPf and pulsatility index values were significantly higher in AKI patients $(0.53 \pm 0.10$ vs. $0.61 \pm 0.10, p<0.001$, and $0.80 \pm 0.03$ vs. $0.82 \pm 0.03, p<0.001$, respectively). The frequency of hypotension, cardiogenic shock, Killip class $>1$, and the use of IABP were higher in patients with AKI compared to those without AKI (48 [4.7\%] vs. 39 [27.3\%], 25 [2.4\%] vs. 26 [18.2\%], 137 [13.3\%] vs. 55 [38.5\%], and 35 [3.4\%] vs. 31 [21.7\%], respectively, $p<0.001$ in each case). The SYNTAX scores and the presence of chronic total occlusion were higher in patients with AKI. Moreover, total ischemic time was longer in patients with AKI than those without AKI (225 min [range 138-325] vs. $167 \mathrm{~min}$ [range $110-252], p<0.001)$. The volume of contrast agent used during revascularization procedures was higher in the AKI group ( $338 \pm 91$ vs. $261 \pm 63 \mathrm{~mL}, p<0.001)$. The inhospital mortality rate was significantly higher in patients with AKI than those without it (27 [18.8\%] vs. 12 [1.2\%], $p<0.001)$. All patients' clinical and angiographic characteristics are detailed in Table 2.

To identify the independent predictors of AKI, multivariable logistic regression analyses were performed using the variables that showed marginal association with AKI in univariable analyses. Among these variables, age (per 1 year), hemoglobin (per $1 \mathrm{~g} / \mathrm{dL}$ ), contrast volume (per $1 \mathrm{~mL}$ ), CRP (per $1 \mathrm{mg} / \mathrm{dL}$ ), and PPf $\times 10$ were taken as continuous variables. Age, hemoglobin, proximal/ostial lesions for IRA, hypotension, contrast volume, CRP, and PPf were found to be related with AKI in univariable and multivariable analysis ( $\mathrm{Ta}$ ble 3). After exclusion of the patients with cardiogenic shock/hypotension, there was not a major change in the results of multivariable logistic regression analyses in 
Table 2. Clinical and angiographic characteristics of all patients and patients classified according to the AKI

\begin{tabular}{|c|c|c|c|c|}
\hline & $\begin{array}{l}\text { All patients } \\
(n=1,170)\end{array}$ & $\begin{array}{l}\text { Patients without } \\
\text { AKI }(n=1,027)\end{array}$ & $\begin{array}{l}\text { Patients with } \\
\text { AKI }(n=143)\end{array}$ & $p$ value \\
\hline Heart rate, bpm & $77 \pm 16$ & $77 \pm 15$ & $81 \pm 21$ & 0.001 \\
\hline $\mathrm{SBP}, \mathrm{mm} \mathrm{Hg}$ & $131 \pm 30$ & $131 \pm 27$ & $130 \pm 49$ & 0.511 \\
\hline $\mathrm{DBP}, \mathrm{mm} \mathrm{Hg}$ & $79 \pm 18$ & $79 \pm 16$ & $74 \pm 28$ & 0.003 \\
\hline $\mathrm{PP}, \mathrm{mm} \mathrm{Hg}$ & $51.8 \pm 15.1$ & $51.3 \pm 13.7$ & $55.9 \pm 22.5$ & 0.113 \\
\hline Arterial pressure, $\mathrm{mm} \mathrm{Hg}$ & $96.0 \pm 21.9$ & $96.5 \pm 19.5$ & $92.4 \pm 34.9$ & 0.067 \\
\hline Pulsatility index & $0.82 \pm 0.03$ & $0.80 \pm 0.03$ & $0.82 \pm 0.03$ & $<0.001$ \\
\hline Hypotension & $87(7.4)$ & $48(4.7)$ & $39(27.3)$ & $<0.001$ \\
\hline Cardiogenic shock & $51(4.4)$ & $25(2.4)$ & $26(18.2)$ & $<0.001$ \\
\hline Killip class $>1$ & $192(16.4)$ & $137(13.3)$ & $55(38.5)$ & $<0.001$ \\
\hline IABP & $66(5.6)$ & $35(3.4)$ & $31(21.7)$ & $<0.001$ \\
\hline LAD as an IRA & $597(51.0)$ & $516(50.2)$ & $81(56.6)$ & 0.152 \\
\hline Total ischemia time, $\min$ & $173(112-261)$ & $167(110-252)$ & $225(138-325)$ & $<0.001$ \\
\hline Contrast volume, $\mathrm{mL}$ & $270 \pm 71$ & $261 \pm 63$ & $338 \pm 91$ & $<0.001$ \\
\hline In-hospital death & $39(3.3)$ & $12(1.2)$ & $27(18.8)$ & $<0.001$ \\
\hline
\end{tabular}

Data are presented as the mean $\pm \mathrm{SD}, n(\%)$, or median (range). AKI, acute kidney injury; SBP, systolic blood pressure; DBP, diastolic blood pressure; PP, pulse pressure; PPf, fractional pulse pressure; IABP, intra-aortic balloon pump; LAD, left anterior descending artery; IRA, infarct related artery; LMCA, left main coronary artery; CTO, chronic total occlusion.

Table 3. Univariable and multivariable logistic regression analysis for the prediction of AKI

\begin{tabular}{llllrr}
\hline & \multicolumn{2}{l}{ Univariable analysis } & & \multicolumn{2}{l}{ Multivariable analysis } \\
\cline { 2 - 3 } & \multicolumn{2}{l}{$p$ value } & OR $(95 \% \mathrm{CI})$ & & \multicolumn{2}{c}{$p$ value } & OR $(95 \% \mathrm{CI})$ \\
\hline Age, years & $<0.001$ & $1.054(1.039-1.070)$ & & $<0.001$ & $1.037(1.018-1.056)$ \\
Haemoglobin & $<0.001$ & $0.765(0.696-0.840)$ & & 0.027 & $0.873(0.775-0.985)$ \\
Proximal/ostial lesion for IRA & $<0.001$ & $3.531(2.307-5.405)$ & & 0.023 & $1.832(1.086-3.090)$ \\
Hypotension & $<0.001$ & $7.648(4.788-12.218)$ & & 0.001 & $2.691(1.472-4.920)$ \\
Contrast volume & $<0.001$ & $1.013(1.011-1.016)$ & & $<0.001$ & $1.011(1.008-1.014)$ \\
CRP & $<0.001$ & $1.043(1.031-1.055)$ & & 0.046 & $1.017(1.000-1.034)$ \\
PPf $\times 10$ & $<0.001$ & $2.183(1.823-2.614)$ & & $<0.001$ & $1.874(1.513-2.322)$ \\
\hline
\end{tabular}

All clinically relevant parameters were included in the model. AKI, acute kidney injury; IRA, infarct related artery; CRP, C-reactive protein; PPf, fractional pulse pressure.

predicting AKI (Table 4). In the ROC analysis, the best cut-off value of the PPf was 0.52 with a sensitivity of $83.2 \%$ and a specificity of $50.3 \%$. The area under the curve (AUC) value for PPf (AUC 0.722; 95\% CI 0.6950.748 ) was significantly higher than AUC for SPB (AUC 0.517; 95\% CI 0.488-0.546), DPB (AUC 0.576; 95\% CI 0.547-0.605), MAP (AUC 0.547; 95\% CI 0.518-0.576), pulsatility index (AUC 0.683 ; 95\% CI $0.625-0.710$ ), and
PP (AUC 0.541; 95\% CI 0.512-0.570; $p<0.005$ for each; Fig. 1).

Even if not optimal, when we reclassified using the criteria of the Acute Kidney Injury Network (AKIN) other than urine output, we diagnosed AKI in 129 patients, and found that we did not underestimate those patients. We compared our definition with AKIN definition, and we found $99.2 \%$ consistency. 
Table 4. Univariable and multivariable logistic regression analysis for the prediction of AKI (all patients with cardiogenic shock/hypotension were excluded from the analysis)

\begin{tabular}{lccccc}
\hline & \multicolumn{2}{l}{ Univariable analysis } & & \multicolumn{2}{l}{ Multivariable analysis } \\
\cline { 2 - 3 } & \multicolumn{2}{c}{$p$ value } & OR $(95 \% \mathrm{CI})$ & & \multicolumn{2}{c}{$p$ value } & OR (95\% CI) \\
\hline Age, years & 0.008 & $1.033(1.009-1.058)$ & & 0.001 & $1.034(1.013-1.056)$ \\
Haemoglobin & 0.036 & $0.845(0.722-0.989)$ & & 0.042 & $0.857(0.738-0.994)$ \\
Proximal/ostial lesion for IRA & 0.016 & $2.116(1.152-3.885)$ & & 0.015 & $1.960(1.140-3.370)$ \\
Heart rate & 0.056 & $1.021(0.999-1.043)$ & & 0.048 & $1.018(1.000-1.037)$ \\
Contrast volume & $<0.001$ & $1.011(1.008-1.014)$ & & $<0.001$ & $1.011(1.008-1.014)$ \\
CRP & 0.027 & $1.023(1.003-1.044)$ & & 0.003 & $1.026(1.009-1.043)$ \\
PPf $\times 10$ & $<0.001$ & $1.853(1.459-2.352)$ & & $<0.001$ & $1.891(1.503-2.378)$ \\
\hline
\end{tabular}

All clinically relevant parameters were included in the model. AKI, acute kidney injury; IRA, infarct related artery; CRP, C-reactive protein; PPf, fractional pulse pressure.

Fig. 1. ROC curve analysis to determine the optimal cut-off values of the PPf, SBP and DBP, MAP, PP, and pulsatility index for the prediction of AKI in STEMI patients.

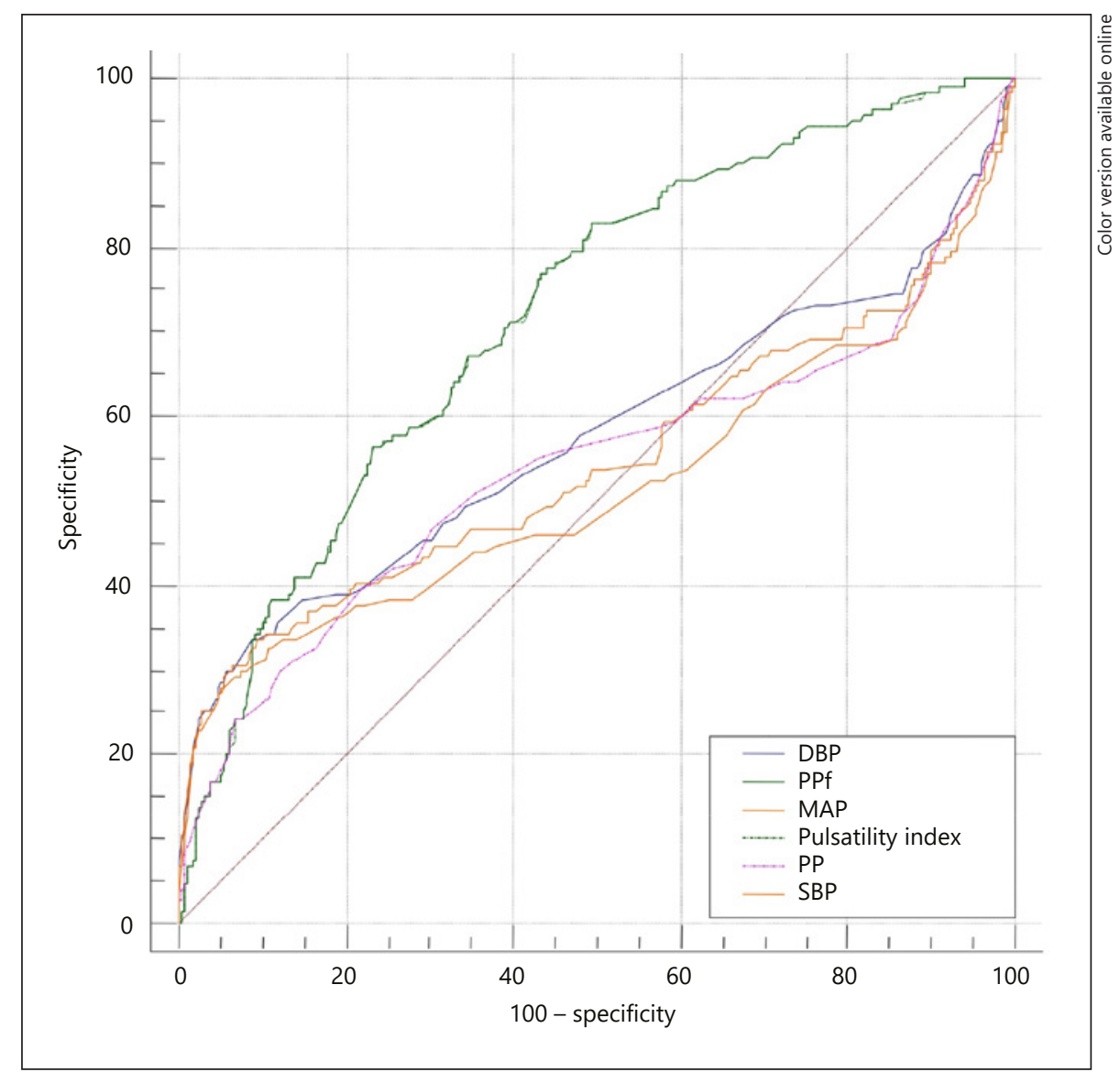

\section{Discussion}

In the present study, we investigated whether PPf was associated with AKI in patients with STEMI who underwent primary PCI. The main finding of our study is that invasively measured PPf is associated with AKI. In addition, PPf may be an independent predictor of AKI in patients with STEMI who underwent primary PCI. To the best of our knowledge, there is no such data in the literature. 
Primary PCI is a vitally important standard treatment option for STEMI patients. However, AKI is a major disadvantage for patients who are treated with primary PCI. $\mathrm{AKI}$ is associated with a longer hospital stay, additional cost, and increased in-hospital and long-term morbidity and mortality [4-6]. The incidence of AKI in patients undergoing emergency PCI due to acute coronary syndrome does not appear to be low, with rates ranging from 13.3 to $28 \%[5,11,12]$. Compared to previous studies, the frequency of AKI in this study was $12.2 \%$, which appeared to be lower. Despite the fact that relatively high rates have been reported in some publications (11\%) [13], when the AKI rates in patients undergoing contrast-enhanced computed tomography are analyzed, the rates of the contrast-induced nephropathy after imaging in the more comprehensive meta-analysis are around $6 \%$, which is lower than the AKI rates seen in STEMI patients [14]. The reasons for a higher incidence of renal impairment observed in STEMI patients may be related not only to the use of contrast agent, but also different hemodynamic and inflammatory variables may be present. Hence, AKI in STEMI patients differs from contrast-induced nephropathy in patients during imaging [13]. To date, several AKI risk factors have been identified such as baseline renal impairment, hypotension, congestive heart failure, diabetes mellitus, advanced age, and anemia $[2,11,15$, 16]. Consistent with prior studies, in this study, AKI patients were older, had lower baseline eGFR, LVEF, and hemoglobin levels, but had higher levels of creatinine and troponin. Hypertension and diabetes mellitus were more frequent in patients with AKI than those without AKI.

Ischemic injury and myocardial necrosis due to STEMI trigger an acute inflammatory process, and an elevated CRP level has been found to be related with AKI development in STEMI patients [17]. During the inflammatory process, increased CRP activates the coagulation system, leads to an increase in the secretion of adhesion molecules, and reduces nitric oxide production [18]. Endothelial dysfunction and decreased renal vasodilator activity have been shown to contribute to AKI development [19]. Consistent with the literature, in this study, CRP was found to be an independent predictor of AKI development. Additionally, in our study, white blood cell counts and glucose levels were higher in AKI patients than those without.

Baseline renal dysfunction and hemodynamic deterioration have a great effect on AKI development, as demonstrated by the Bremen registry study, in which the researchers investigated AKI predictors in STEMI patients. Based on this study finding, many parameters have been used in many risk classifications $[5,11,15]$. Hemodynam-

The Association of Fractional Pulse Pressure with Acute Kidney Injury ic impairment may precipitate reduction in renal blood flow and lead to activation of the renin-angiotensin-aldosterone and sympathetic systems. All of these changes can ultimately lead to renal vasoconstriction and renal medullary hypoxia, resulting in AKI development. Because of the longer duration of the renal elimination of contrast media and prolonged exposure to the toxic agents, AKI rates are higher in patients with initial renal dysfunction [20]. Evaluating the current study results from this perspective, the frequency of hypotension, shock, Killip class $>1$, and the use of IABP, all of which are consequences of a deteriorated hemodynamic status, were higher in patients with AKI than those without, which is in line with the current literature. Peripheral arterial disease was also significantly associated with major adverse cardiac events in acute coronary syndrome patients [21]. Higher SYNTAX scores have been correlated with AKI development, more adverse cardiac events, and the need for hemodialysis in patients with acute coronary syndrome $[22,23]$. In parallel with the literature, in the current study, the SYNTAX score was higher in patients with AKI than those without. Additionally, the rate of proximal/ostial lesions for IRA and the presence of chronic total occlusion was higher in patients with AKI. We considered that the underlying reasons may be the longer procedure duration, the use of a higher contrast media volume, and greater ischemic myocardial volume.

$\mathrm{PP}$, which is the difference between SBP and DBP, reflects aortic stiffness [24]. As stiffening of the central elastic vessels causes greater reflected waves in the early systole, it increases PP in general. Large cohort studies have demonstrated the relationship between PP and adverse cardiovascular events [7, 25]. However, Mahfouz et al. [8] showed that PPf is superior to PP in predicting aortic stiffness. Their hypothesis was that dividing the PP by MAP excludes the impact of cardiac output and peripheral vascular resistance. As renal microvascular resistance is very low and the kidneys are perfused at high-flow volume throughout the systole and diastole, it has been suggested that excessive pulsatile energy transmission into the susceptible renal microvasculature causes progression of kidney damage [26]. In other studies, acceleration in aortic stiffening is related with renal function deterioration $[27,28]$. However, evaluating aortic stiffness can be difficult and time-consuming in STEMI patients before a PCI procedure. We hypothesized that increased $\mathrm{PPf}$, which is associated with aortic stiffness, could be associated with AKI. In addition to the known risk factors, we found that PPf was also an independent predictor of AKI in STEMI patients. We considered that both low 
MAP and high PP have a significant effect on renal impairment in STEMI patients undergoing primary PCI. Therefore, PPf, by combining both of these, may be a valid independent predictor of AKI.

Some limitations should be noted regarding the present study. It had a retrospective design and only in-hospital data were available. Therefore, no inferences on long-term results could be made. We did not have urine outputs of all patients, so we could not use the RIFLE (risk, injury, failure, loss of kidney function, and endstage kidney disease) or the AKIN classifications [29, 30]. Since the endpoint of the study was AKI, other adverse events were not evaluated. Although well-known risk factors have been evaluated in the study, some residual unmeasured confounders might have affected our results. Due to the retrospective nature of the study, the arterial stiffness indices were absent and could not be investigated in relation to PPf.

\section{Conclusion}

The present study demonstrates that PPf is an independent predictor of AKI in STEMI patients treated with primary PCI. In addition, PPf is superior to other blood pressure values and derivatives in AKI prediction. Based on our results, the use of PPf in AKI prediction may play an important role in the management of these patients.

\section{Statement of Ethics}

The Kafkas University Ethics Committee reviewed and approved the current study protocol in accordance with the principles of the Declaration of Helsinki.

\section{Conflict of Interest Statement}

The authors have no conflicts of interest to declare. This research did not receive any specific grant from funding agencies in the public, commercial, or not-for-profit sectors.

\section{Author Contributions}

C.B., I.Y., M.S., and I.R.: study conception. C.B., M.C., Y.K., and I.Y.: study design. E.B., I.R., and M.C.: supervision. C.B., M.S., M.Y., I.Y., D.I., and S.H.: data collection/processing. C.B., Y.K., E.B., I.Y., Ş.H., and D.İ.: analysis/interpretation. C.B., M.S., D.I., M.Y. and Ş.H.: literature review. C.B., Y.K., M.C., and I.R.: writing. E.B., C.B., Y.K., and I.R.: critical review.

\section{References}

1 Rihal CS, Textor SC, Grill DE, Berger PB, Ting $\mathrm{HH}$, Best PJ, et al. Incidence and prognostic importance of acute renal failure after percutaneous coronary intervention. Circulation. 2002 May;105(19):2259-64.

2 McCullough PA, Wolyn R, Rocher LL, Levin $\mathrm{RN}, \mathrm{O}$ 'Neill WW. Acute renal failure after coronary intervention: incidence, risk factors, and relationship to mortality. Am J Med. 1997 Nov;103(5):368-75.

3 Marenzi G, Lauri G, Assanelli E, Campodonico J, De Metrio M, Marana I, et al. Contrastinduced nephropathy in patients undergoing primary angioplasty for acute myocardial infarction. J Am Coll Cardiol. 2004 Nov;44(9): $1780-5$.

4 Fox CS, Muntner P, Chen AY, Alexander KP, Roe MT, Wiviott SD. Short-term outcomes of acute myocardial infarction in patients with acute kidney injury: a report from the national cardiovascular data registry. Circulation. 2012 Jan;125(3):497-504.

5 Schmucker J, Fach A, Becker M, Seide S, Bünger S, Zabrocki R, et al. Predictors of acute kidney injury in patients admitted with STelevation myocardial infarction - results from the Bremen STEMI-Registry. Eur Heart J Acute Cardiovasc Care. 2018 Dec;7(8):71022.
6 Çınar T, Tanık VO, Aruğaslan E, Karabağ Y, Çağdaş M, Rencüzoğulları İ, et al. The association of PRECISE-DAPT score with development of contrast-induced nephropathy in patients with ST-elevation myocardial infarction undergoing primary percutaneous coronary intervention. Cardiovasc Interv Ther. 2019 Jul;34(3):207-15.

7 Franklin SS, Khan SA, Wong ND, Larson MG, Levy D. Is pulse pressure useful in predicting risk for coronary heart Disease? The Framingham heart study. Circulation. 1999 Jul;100(4):354-60.

8 Mahfouz RA, Elawady W, Abdu M, Salem A. Associations of fractional pulse pressure to aortic stiffness and their impact on diastolic function and coronary flow reserve in asymptomatic diabetic patients with normal coronary angiography. Cardiol J. 2013;20(6):60511.

9 Mehran R, Nikolsky E. Contrast-induced nephropathy: definition, epidemiology, and patients at risk. Kidney Int Suppl. 2006 Apr; 69(100):S11-5.

10 O'Rourke MF, Safar ME. Relationship between aortic stiffening and microvascular disease in brain and kidney: cause and logic of therapy. Hypertension. 2005 Jul;46(1): $200-4$.
11 Abusaada K, Yuan C, Sabzwari R, Butt K, Maqsood A. Development of a novel score to predict the risk of acute kidney injury in patient with acute myocardial infarction. J Nephrol. 2017 Jun;30(3):419-25.

12 Senoo T, Motohiro M, Kamihata H, Yamamoto $\mathrm{S}$, Isono $\mathrm{T}$, Manabe $\mathrm{K}$, et al. Contrastinduced nephropathy in patients undergoing emergency percutaneous coronary intervention for acute coronary syndrome. Am J Cardiol. 2010 Mar;105(5):624-8.

13 Mitchell AM, Jones AE, Tumlin JA, Kline JA. Incidence of contrast-induced nephropathy after contrast-enhanced computed tomography in the outpatient setting. Clin J Am Soc Nephrol. 2010 Jan;5(1):4-9.

14 Moos SI, van Vemde DN, Stoker J, Bipat S. Contrast induced nephropathy in patients undergoing intravenous (IV) contrast enhanced computed tomography (CECT) and the relationship with risk factors: a metaanalysis. Eur J Radiol. 2013 Sep;82(9):e38799.

15 Mehran R, Aymong ED, Nikolsky E, Lasic Z, Iakovou I, Fahy M, et al. A simple risk score for prediction of contrast-induced nephropathy after percutaneous coronary intervention: development and initial validation. J Am Coll Cardiol. 2004 Oct;44(7):1393-9. 
16 Marenzi G, Cabiati A, Bertoli SV, Assanelli E, Marana I, De Metrio M, et al. Incidence and relevance of acute kidney injury in patients hospitalized with acute coronary syndromes. Am J Cardiol. 2013 Mar;111(6):816-22.

17 Shacham Y, Leshem-Rubinow E, Steinvil A, Keren G, Roth A, Arbel Y. High sensitive Creactive protein and the risk of acute kidney injury among ST elevation myocardial infarction patients undergoing primary percutaneous intervention. Clin Exp Nephrol. 2015 Oct; 19(5):838-43.

18 Fujii H, Li SH, Szmitko PE, Fedak PW, Verma S. C-reactive protein alters antioxidant defenses and promotes apoptosis in endothelial progenitor cells. Arterioscler Thromb Vasc Biol. 2006 Nov;26(11):2476-82.

19 Russo D, Minutolo R, Cianciaruso B, Memoli B, Conte G, De Nicola L. Early effects of contrast media on renal hemodynamics and tubular function in chronic renal failure. J Am Soc Nephrol. 1995 Nov;6(5):1451-8.

20 Heinrich MC, Kuhlmann MK, Grgic A, Heckmann M, Kramann B, Uder M. Cytotoxic effects of ionic high-osmolar, nonionic monomeric, and nonionic iso-osmolar dimeric iodinated contrast media on renal tubular cells in vitro. Radiology. 2005 Jun; 235(3):843-9.
21 Al-Zakwani I, Al Siyabi E, Alrawahi N, AlMulla A, Alnaeemi A, Shehab A, et al. Association between Peripheral Artery Disease and Major Adverse Cardiovascular Events in Patients with Acute Coronary Syndrome: Findings from the Gulf COAST Registry. Med Princ Pract. 2019;28(5):410-7.

22 Madhavan MV, Généreux P, Rubin J, Palmerini T, Caixeta A, Xu K, et al. Usefulness of the SYNTAX score to predict acute kidney injury after percutaneous coronary intervention (from the Acute Catheterization and Urgent Intervention Triage Strategy Trial). Am J Cardiol. 2014 Apr;113(8):1331-7.

23 Aktürk E, Așkın L, Taşolar H, Türkmen S, Kaya H. Comparison of the predictive roles of risk scores of in-hospital major adverse cardiovascular events in patients with non-ST elevation myocardial infarction undergoing percutaneous coronary intervention. Med Princ Pract. 2018;27(5):459-65.

24 Dart AM, Kingwell BA. Pulse pressure - a review of mechanisms and clinical relevance. J Am Coll Cardiol. 2001 Mar;37(4):975-84.

25 Benetos A, Safar M, Rudnichi A, Smulyan H, Richard JL, Ducimetieère $P$, et al. Pulse pressure: a predictor of long-term cardiovascular mortality in a French male population. Hypertension. 1997 Dec;30(6):1410-5.
26 Townsend RR, Wimmer NJ, Chirinos JA, Parsa A, Weir M, Perumal K, et al. Aortic PWV in chronic kidney disease: a CRIC ancillary study. Am J Hypertens. 2010 Mar;23(3): 282-9.

27 Yannoutsos A, Bahous SA, Safar ME, Blacher J. Clinical relevance of aortic stiffness in endstage renal disease and diabetes: implication for hypertension management. J Hypertens. 2018 Jun;36(6):1237-46.

28 van Varik BJ, Vossen LM, Rennenberg RJ, Stoffers HE, Kessels AG, de Leeuw PW, et al. Arterial stiffness and decline of renal function in a primary care population. Hypertens Res. 2017 Jan;40(1):73-8.

29 Bellomo R, Ronco C, Kellum JA, Mehta RL, Palevsky P; Acute Dialysis Quality Initiative workgroup. Acute renal failure - definition, outcome measures, animal models, fluid therapy and information technology needs: the Second International Consensus Conference of the Acute Dialysis Quality Initiative (ADQI) Group. Crit Care. 2004 Aug;8(4): R204-12.

30 Mehta RL, Kellum JA, Shah SV, Molitoris BA, Ronco C, Warnock DG, et al.; Acute Kidney Injury Network. Acute Kidney Injury Network: report of an initiative to improve outcomes in acute kidney injury. Crit Care. 2007; 11(2):R31.
The Association of Fractional Pulse Pressure with Acute Kidney Injury
Med Princ Pract 2020;29:572-579 